\title{
0 estágio curricular como práxis pedagógica: representações sociais acerca da criança com deficiência físico-motora entre estudantes de Fisioterapia*
}

Leandro Dias de Araujo(a)

Ana Lucia de Souza Freire Santos(b)

Adriano Rosa ${ }^{(c)}$

Marta Corrêa Gomes ${ }^{(d)}$

Araujo LD, Santos ALSF, Rosa A, Gomes MC. The curriculum internship as pedagogical praxis: social representations regarding children with physical motor deficiency among physiotherapy students. Interface (Botucatu). 2014; 18(48):151-64.

This paper analyses the transformation of social representations among physiotherapy students, regarding children with physical motor deficiency, influenced by internships on pediatric physiotherapy. In posing this issue, we took into consideration the stigmatized manner in which people with deficiencies are represented and the influence of supervised curriculum internships on undergraduate healthcare training. This was a qualitative study on 24 students entering and leaving pediatric physiotherapy internships, who participated in semi-structured interviews and focus groups. This study made it possible to infer that the representations were fundamentally provided through the experience of the internship, although the theoretical and conceptual disciplines furnished technical support for the intervention. In this manner, the curriculum needs to emphasize the internship as knowledge and praxis, since the gains transcend the change in the way that deficiency is regarded, bringing incomparable benefits and professional resources, as well as personal values that are essential for shaping human character.

Keywords: Education. Health Education. Physiotherapy. Rehabilitation. Child.
O artigo analisa a transformação das representações sociais dos alunos de fisioterapia acerca da criança com deficiência físico-motora, influenciada pelo estágio em fisioterapia pediátrica. Consideramos, para a problematização, o modo estigmatizado como as pessoas com deficiência são representadas, e a influência do estágio curricular supervisionado na formação acadêmica em saúde. A pesquisa, de caráter qualitativo, contou com 24 alunos ingressantes e egressos do estágio em fisioterapia pediátrica, submetidos a entrevistas semiestruturadas e grupo focal. O estudo permitiu inferir que as representações são possibilitadas, fundamentalmente, pela experiência do estágio, embora as disciplinas teóricoconceituais forneçam subsídios técnicos para a intervenção. Dessa forma, o currículo deve enfatizar o estágio como conhecimento e práxis, uma vez que os ganhos extrapolam a mudança na forma de ver a deficiência, trazendo benefícios e recursos profissionais incomparáveis, além de valores pessoais essenciais para a formação humana.

Palavras-chave: Educação. Formação em saúde. Fisioterapia. Reabilitação. Criança.
Elaborado com base
em dissertação de
estrado' aprovada pelo
Comitê de Ética em
Pesquisa envolvendo
Seres Humanos da
Universidade Gama
Filho.
Mestrado Profissional
em Ensino na Saúde,
Universidade Gama
Filho, Rio de Janeiro.
Travessa Coari, 53,
Abolição. Rio de
Janeiro, RJ, Brasil.
20755-030.
eandiar@hotmail.com;
alufsan@gmail.com;
66.rosa@gmail.com;
martacorreagomes@
yahoo.com.br (n) 


\title{
Introdução
}

A deficiência físico-motora (DFM) ou deficiência física não sensorial é descrita pelo Decreto Federal no 3.298 de 20/12/19992:

\begin{abstract}
uma alteração completa ou parcial de um ou mais segmentos do corpo humano, acarretando o comprometimento da função física, apresentando-se sob a forma de paraplegia, paraparesia, monoplegia, monoparesia, tetraplegia, tetraparesia, triplegia, triparesia, hemiplegia, hemiparesia, ostomia, amputação ou ausência de membro, paralisia cerebral, nanismo, membros com deformidade congênita ou adquirida, exceto as deformidades estéticas e as que não produzam dificuldades para o desempenho de funções.
\end{abstract}

Na educação, o termo DFM foi uniformizado a partir do "Referencial Curricular Nacional para a Educação Infantil: estratégias e orientações para a educação de crianças com necessidades educacionais especiais" ${ }^{3}$, com o objetivo de subsidiar a realização do trabalho educativo junto às crianças que apresentam necessidades especiais, na faixa etária de zero a seis anos.

De acordo com Israel e Bertoldi ${ }^{4}$, a DFM afeta as possibilidades de movimento, a coordenação motora e o equilíbrio para a execução de atividades do cotidiano, que acompanha o indivíduo desde o nascimento, ou pode ser adquirida na vida adulta se mantendo de forma permanente ou transitória.

A despeito das classificações técnico-biomédicas, a deficiência é um fenômeno que, embora se manifeste individualmente, é construído socialmente, pois, em cada contexto social e histórico, sua representação adquire características diferentes, na medida em que seu fundamento se encontra nos julgamentos sociais sobre as diferenças que consideram o corpo ou o comportamento disfuncional e "anormal", algo atípico e "deficiente", 5 e ainda englobam outras concepções ligadas a crenças ou mitos, que influenciam as atitudes de segregação social ${ }^{6}$.

A imagem da deficiência explicita, imediatamente, a diferença, e a diferença perturba padrões sociais. A deficiência é uma das diferenças, sobretudo as estampadas no corpo, que negam os padrões da aparência, da funcionalidade e ferem a harmonia corporal ${ }^{6,7}$.

As diferenças impossibilitam a identificação com o outro, onde essa modificação desfavorável é socialmente transformada em estigma. Em outra perspectiva, a aparência intolerável chama a atenção para a condição frágil do homem, criando uma desordem na segurança ontológica e suscitando o assombro do imaginário do corpo desmantelado ${ }^{8}$.

As muitas marcas presentes no corpo caracterizado pela imobilidade, descontrole, assimetria, rigidez, tremor, amputação, forma e expressão não verbal, provocam um imediatismo de identificação da deficiência, influenciando diretamente na exclusão e inclusão social, já que, no cotidiano do convívio social, os padrões de "normalidade", impostos por essa sociedade, regem o que é desviante, deficiente ou eficiente 9 .

Goffman ${ }^{10}$ afirma que, quando um estigma é imediatamente perceptível, permanece a questão de se saber até onde vai interferir no fluxo da interação social, já que o que determina se uma condição é estigmatizante ou não é a representação que possui no contexto das relações entre o atributo - o que é próprio e peculiar de alguém - e o estereótipo - ideia classificatória preconcebida sobre alguém.

Vaitsman ${ }^{11}$ demonstra que os processos sociais mais inclusivos são cada vez mais dificultados, na medida em que se atribuem qualidades negativas à diferença, atingindo a dignidade da pessoa, o que produz, como efeito do estereótipo, a segregação social e simbólica. Por outro lado, Omote ${ }^{12}$ afirma que o estigma é parte fundamental da inclusão e cumpre sua função de controle social para a manutenção da vida coletiva - e esse é um grande dilema a ser enfrentado, já que as sociedades humanas "precisam" combater as desigualdades.

Verifica-se, em alguns estudos, tanto no campo pedagógico quanto no campo da intervenção em saúde, que a representação social sobre a deficiência acaba por orientar as práticas de intervenção profissional na promoção e reprodução de visões sociais preconceituosas, prejudicando, assim, o próprio interesse dos acadêmicos em atender a este público em particular ${ }^{13,14}$. 
Lomônaco, Cazeiro e Ferreira ${ }^{15}$ demonstram que a formação predominantemente biomédica do fisioterapeuta, baseada na ênfase dada aos aspectos de lesão, limitação física/funcional e dificuldade das pessoas com deficiência, mesmo após os quatro anos de formação acadêmica, influenciou na permanência dos estereótipos ligados ao senso comum, apresentando estes pacientes como pessoas limitadas, incapacitadas e necessitadas permanentemente de ajuda.

Podemos dizer que estas imagens introduzem ou reforçam um núcleo figurativo ou paradigma ${ }^{16}$ mais aceito socialmente, dando, aos indivíduos, facilidade para falar dele, utilizando termos e expressões mais usados frequentemente, uma vez que estas são as mais familiares e acessíveis.

Não podemos perder de vista que o mundo social é internalizado a partir dos primeiros momentos de vida. Na socialização primária, as formas de ver o mundo vão sendo apropriadas e significadas a partir do lugar social em que os indivíduos estão inseridos ${ }^{17}$. Ao interagirem com outras esferas institucionais, os indivíduos podem vir a reproduzir os padrões de pensamento e comportamento, reforçar valores, crenças e representações, ou trazer rupturas, formando outras possibilidades de "ver" o mundo, frequentemente estimuladas em função da imersão em grupos de referência com diferentes pensamentos e identidades, desde os primeiros anos pelo contexto escolar, até a formação universitária, pelo trabalho, dentre outras instituições.

Observamos, no presente estudo, que, no caso do atendimento à criança com DFM pelos alunos de fisioterapia, percebe-se que o desconhecimento, a falta de contato físico no cotidiano, sentimentos de estranheza e pena, acabam promovendo a rejeição, dificultando a relação paciente-fisioterapeuta e interferindo no "fluxo de interação"10. Os alunos, inseridos num contexto sociocultural produtor de ideários de corpos perfeitos, normais, parecem estranhar os corpos qualificados abaixo dos padrões de normalidade, uma vez que, em muitos casos de DFM, o descontrole é o padrão. Nesse sentido, é comum, entre alunos, algum comportamento de evitação do paciente com deficiência e o receio na aproximação, parecendo que a deficiência, para eles, é, antropologicamente falando, um tabu ${ }^{18}$.

Ceccim e Feuerwerker ${ }^{19}$ destacam que a formação profissional em saúde precisa romper definitivamente com o modelo biomédico fragmentado de ensino e intervenção, voltando-se para metodologias que garantam a problematização e a reflexão crítica dos alunos envolvidos. Diferentes estudos científicos sobre a formação em fisioterapia apontam para a necessidade de mudanças curriculares que abranjam também conhecimentos nas áreas de ciências humanas, sociais e pedagógicas ${ }^{20-27}$. Tais estudos demonstram que a formação em fisioterapia permanece com um enfoque hegemonicamente biomédico, refletindo a fragmentação do conhecimento e o seu distanciamento na relação teoria e prática, situação que pode ser observada no estágio em fisioterapia.

O estágio supervisionado em fisioterapia pediátrica é fundamental para a formação profissional, uma vez que coloca o aluno frente às dificuldades da atividade terapêutica e da relação com a criança enquanto paciente. Espera-se a articulação entre os diversos campos de conhecimento que implicam a intervenção, propiciando a identificação de novos cenários sociais, a reflexão crítica a partir de um novo processo de socialização e a possibilidade de repensar a prática e os próprios conceitos que a orientam. Nesta perspectiva, Gadotti ${ }^{28}$ enfatiza a necessidade da formação a partir de uma pedagogia da práxis, visto que a práxis é um exercício que se faz pela transformação da natureza e da sociedade a partir da atividade humana diante do mundo, da sociedade e do próprio homem. O ato de ensinar e aprender descontextualizado da práxis não transforma ${ }^{29}$

Logo, o estágio precisa garantir, ao aluno, a vivência com os princípios e diretrizes do Sistema Único de Saúde, dos quais o da integralidade parece ser o menos visível na trajetória do sistema, de suas práticas e, no nosso caso, da formação em fisioterapia ${ }^{20-27}$. O princípio da integralidade pressupõe a relação intersubjetiva na qual o profissional se relaciona com sujeitos, e não com objetos, envolvendo necessariamente uma dimensão dialógica e dialética, possibilitando identificar as necessidades de ações sintonizadas com o contexto específico de cada sujeito em suas singularidades, garantindo a relevância do que é trazido por eles e suas famílias no que diz respeito aos seus sofrimentos, expectativas, temores e desejos ${ }^{30}$.

Este estudo buscou analisar as transformações das representações dos alunos de fisioterapia acerca da criança com DFM e o papel do estágio curricular supervisionado em fisioterapia pediátrica neste 
processo. O estágio, ao permitir a ponte entre teoria e prática, possibilita um rito de passagem para a construção dessa nova identidade que demanda uma visão dinâmica do cotidiano: do aluno de fisioterapia ao fisioterapeuta sensibilizado a lidar com as diferenças.

\section{Procedimentos metodológicos}

Este artigo é parte de uma pesquisa mais ampla sobre estágio, práxis e representações sociais acerca da criança com DFM, entre alunos de fisioterapia de uma universidade privada do Rio de Janeiro ${ }^{1}$. $O$ estudo, de caráter qualitativo e exploratório, contou com 24 sujeitos selecionados a partir de duas categorias de representação em termos de extrato no campo: Alunos Iniciantes (AI), grupo formado por alunos devidamente matriculados no curso de Fisioterapia que já haviam cumprido até cinquenta por cento da carga horária total do curso no início da coleta de dados e que ainda não haviam cursado a disciplina de Fisioterapia em Pediatria; e Alunos egressantes do estágio no setor de Fisioterapia Pediátrica da Clínica Escola de Fisioterapia da própria universidade. Esse grupo foi reorganizado em dois subgrupos, Alunos Egressantes 1 (AE1) e Alunos Egressantes 2 (AE2), como estratégia metodológica, no sentido de aumentar a confiabilidade dos dados a partir da aplicação de diferentes instrumentos de investigação: a entrevista semiestruturada e o grupo focal ${ }^{31}$.

As entrevistas realizadas com os Al e com os AE1 foram gravadas e guiadas por roteiro semiestruturado $^{32}$. O grupo focal foi realizado, pelo pesquisador, com o grupo de AE2 na presença de dois moderadores. Foi utilizado um roteiro de três perguntas deflagradoras contendo os seguintes aspectos: as possíveis mudanças ocorridas nas representações sociais acerca da DFM; a que fatores da sua formação eles atribuem essa mudança; e as influências do estágio na sua formação profissional e pessoal. Conforme afirma Morgan ${ }^{33}$, o grupo focal difere da entrevista em grupo, já que não é apenas uma sequência de perguntas e respostas, e sim envolvimento e interação entre os participantes durante a discussão.

Após a coleta de dados, foi realizada a transcrição das falas, a pré-análise e a categorização a partir da análise dos seus conteúdos com relação aos objetivos propostos pela pesquisa, obedecendo as fases de descrição, inferência e interpretação ${ }^{34}$. Considerou-se, como critério de relevância central, as respostas categorizadas de forma mais frequente e primeiramente evocadas - Núcleos Centrais (NC). As demais categorias foram analisadas como sistemas periféricos de importância (SP), que dialogam com as categorias centrais, complementando-as, ou mesmo, trazendo ambiguidades. As falas do grupo focal foram gravadas, transcritas e submetidas à análise temática.

A pesquisa foi aprovada pelo Comitê de Ética em Pesquisa envolvendo Seres Humanos da Universidade Gama Filho, em 07/10/2011, pelo Parecer 144.2011, e todos os sujeitos envolvidos assinaram voluntariamente o termo de consentimento livre e esclarecido e receberam a cópia deste termo ${ }^{35}$.

\section{Resultados e discussão}

\section{Significação e ressignificação da deficiência}

Intencionamos verificar a compreensão do termo DFM pelos alunos de fisioterapia a fim de identificar em que conceitos e valores ancoram-se as suas representações e quanto estão baseadas nos aspectos teórico-científicos.

A partir das falas dos Al, pudemos organizar as respostas e observar que os alunos definem a deficiência como uma dificuldade de movimentos, deficiência das habilidades motoras e dificuldade de coordenação, entre outras, em consonância com o conceito sugerido por Israel e Bertoldi ${ }^{4}$, o que nos leva a identificar, nas falas dos sujeitos, a apropriação inicial de uma linguagem mais científica, como pode ser exemplificado nas seguintes falas: 
"É quando uma pessoa tem dificuldade de realizar algum movimento". (Al8)

“É uma deficiência das habilidades motoras que pode ser temporária ou definitiva...". (AI1)

Observa-se, também, uma visão interpretativa dos alunos sobre a DFM mais baseada no senso comum e na observação empírica do cotidiano, sugerindo os reflexos, dificuldades e limitações que essas pessoas podem ter em virtude de sua deficiência.

A análise de como é feita a construção do conhecimento ao longo da trajetória no curso de fisioterapia, a partir do ementário das disciplinas teórico-conceituais, nos possibilitou associar o contato do aluno com conceitos, classificações e tipificações a certa familiarização conceitual sobre a DFM. Como estes alunos ainda não passaram pela disciplina de estágio supervisionado, o contato físico e direto com essas crianças ainda não ocorreu, e o suporte (repertório de classificação) para dar respostas definitivas e claras a esta pergunta parece ser ainda frágil, em processo de reenquadramento.

A definição da DFM aparece ancorada por conceitos mais próximos e imediatos, aqueles apreendidos dos sistemas universais classificatórios do domínio da fisioterapia ou do conhecimento biomédico em geral. Assim como no exemplo dado por Moscovici, ${ }^{16}$ ao explicar a ideia de ancoragem sendo semelhante a "ancorar um bote perdido em um dos boxes (pontos de sinalização) de nosso espaço social", os elementos incorporados no processo teórico-formativo desses alunos são aqueles que dão o suporte a estas representações, já que representar é classificar e escolher, dentre as possibilidades estocadas em nossa memória, algum paradigma, alguma base que permita transitar, mesmo vagamente, diante de algo ou de uma situação não usual.

Foi também possível observar que os AI representam a criança com DFM pela diferença, mas com uma condição inferior apontada pela anormalidade, denunciada pelo corpo disforme, pela assimetria, pela falta e pela necessidade de auxílio e órteses, como postula Pereira ${ }^{6}$.

“... então... eles sabem que crianças normais estudam, brincam, correm e eles não podem fazer isso...". (Al 7)

Podemos verificar claramente, nas falas, a presença do estigma, já que a DFM em crianças é representada como um atributo que, além de torná-las diferentes das outras crianças, produz efeito depreciativo, de descrédito, de fraqueza, de incapacidade, como a desvantagem no ato de brincar. Segundo Goffman, ${ }^{10}$ quando existe uma preconcepção sobre algo ou alguém, nós a transformamos em expectativas normativas e "exigimos" os padrões esperados para enquadrarmos ou incluí-las em certa categoria. Neste caso, observa-se a presença de suposições feitas sobre como as crianças deveriam ser e como estas crianças supostamente são. Há idealização da liberdade de gestos, da exploração do corpo frente à natureza, ao espaço e aos outros corpos infantis; há o sentimento de que o corpo é o próprio lugar do lúdico.

A ideia de doença, muito presente no senso comum, é ainda encontrada no sistema periférico de representações dos $\mathrm{A} 1 \mathrm{e}$, como sistema particular de categoria, coloca a DFM em oposição à saúde enquanto idealização do corpo e do seu funcionamento sem deformações ou aparente limitações.

Ao perguntarmos aos alunos egressantes o que entendiam sobre o termo DFM, observamos uma maior percepção geral sobre o tema apontando para as dificuldades (dificuldade de locomoção, comunicação, aprendizado motor e a defasagem cognitiva), e o reforço da ideia da dificuldade de movimento, já destacada pelos Al como núcleo central.

Observamos que os alunos AE1 além de atribuírem novos conteúdos teóricos à conceituação, não citaram a categoria "pessoa doente" para definir a criança com DFM. Esta representação, bastante dominante no senso comum, parece ceder à noção mais científica compreendida como sequela neuromotora, traduzida, no corpo, por transtornos de tônus, postura e expressão motora.

Este é um ponto importante para a discussão sobre as representações sociais, pois não podemos considerar que somente os saberes populares ou o senso comum são a sua expressão. Vemos em Moscovici ${ }^{36}$ que as representações sociais podem ser encontradas sob outras formas, além dos saberes 
do senso comum, como nas ciências, nas religiões, nas ideologias, entre outras. O que torna uma representação social paradigmática são justamente as forças de poder e da linguagem que são exercidas sobre ela e através dela. Como afirma Gusmão, ${ }^{37}$ a interação envolve linguagem, cultura e alteridade, que são elementos complementares e conflitivos, sendo a alteridade o maior desafio das culturas.

O conceito teórico sobre a deficiência entre os AE1 é ainda ampliado em comparação com os Al, podendo ser compreendido em duas subunidades temáticas: características específicas e características associadas. As características específicas ligadas à própria definição apontada por Israel e Bertoldi ${ }^{4}$, assim como pelo Decreto Federal n 3.298 de 20 de dezembro de 1999². Já as características associadas sinalizam as principais dificuldades e defasagem associadas.

Os alunos foram indagados sobre que sentimentos eram gerados ao verem ou pensarem em uma criança com DFM. Na análise das entrevistas com os Al, observou-se que as respostas se centralizavam na ideia de pena, tristeza, de negação da tristeza e de solidariedade.

"Acho que não seria tristeza... mas seria de cuidar, de poder ajudar". (Al8)

Os AE1 afirmaram que os sentimentos gerados sobre a DFM antes do estágio eram de pena, preconceito e indignação.

"Via um pouco com pena e não com esperança como atualmente". (AE1 1)

"Antes eu achava que era uma coisa terrível... hoje em dia não". (AE1 4)

Ressaltamos a importância da comparação entre os dois grupos de alunos (Al e AE1) uma vez que o sentimento de pena dos AE1 antes do estágio é muito semelhante ao dos Al que ainda não passaram pelo estágio. Tal sentimento pode ser explicado pelo imediatismo de identificação das marcas presentes no corpo ${ }^{9}$ que exerce um fator importante na representação social da DFM, traduzido em sentimentos de pena, tristeza e impotência. Esta categoria analítica nos dá pistas sobre a falta de familiarização com esta realidade, que, ao nosso olhar, pode ser minimizada pela experiência do estágio supervisionado, dentre outras ações que privilegiem a vivência e o encontro com as diferenças.

Destacamos, também, que sentimentos de piedade acabam por favorecer o comportamento de evitação desta realidade e o receio de aproximação como produto do próprio tabu, como observado por Rodrigues $^{18}$ e Le Breton, ${ }^{8}$ no que diz respeito à dificuldade de lidar com um corpo que não é o espelho do seu próprio corpo.

Ao serem questionados sobre os sentimentos gerados ao verem ou pensarem em uma criança com DFM após o estágio, observamos que algumas das categorias se repetiram, entretanto, a negação da pena aparece como núcleo central, seja por autoproteção aos supostos julgamentos que o pesquisador poderia fazer, seja pela própria reflexão crítica sobre um sentimento bastante comum socialmente, mas que, agora, precisaria ser evitado pela condição de expectativa gerada no futuro profissional, ou pela real mudança das representações.

"Tem pessoas que ficam com pena, eu não fico com pena". (AE1 3)

"Não é pena, mas eu não sei explicar o que é". (AE1 8)

As falas dos AE1 revelam a mudança dos sentimentos em comparação com as percepções antes do estágio, uma vez que a relação com essas crianças trouxe esclarecimento acerca dos seus comportamentos e atitudes em relação a sua própria deficiência, ou seja: há um nítido deslocamento da percepção da deficiência como um tabu à aproximação desta realidade e de uma nova forma de ver estas crianças.

"Via um pouco com pena e não com esperança como atualmente". (AE1 1) 
"Antigamente eu olhava e dizia, coitado. Hoje eu sei que posso fazer alguma coisa... antes eu não tinha essa visão". (AE1 3)

"Antes eu achava que era uma coisa terrível... hoje em dia não". (AE1 4)

"Eu sentia pena da criança, mas depois que fui para o estágio eu vi que elas são felizes do jeito delas". (AE1 7)

Para esta reflexão, recorremos a Gusmão ${ }^{37}$ por observar que a imagem social da infância ainda é uma construção dos adultos a partir de seus contextos sociais vividos, logo, ela é, na maioria das vezes, imprecisa. Neste sentido, podemos afirmar que as representações sobre a criança com DFM podem amplificar, por sua condição de fatalidade precoce: os pré-julgamentos sociais, as diferenças que consideram o corpo ou o comportamento disfuncional e "anormal", algo atípico e "deficiente", como já afirmou Maia ${ }^{5}$. Quando os Al apresentam consequências, em geral negativas para a vida dessas crianças, em especial a dificuldade no brincar, temos, como observação, uma forte impressão de que a representação da criança como ente sagrado, puro, ainda perfeito e possível, não somente cria uma identidade social virtual sobre a infância e suas possibilidades, como pode distanciar ainda mais a apropriação sobre as reais condições, possibilidades e impossibilidades da criança com DFM. Amplia-se a imprecisão sobre a avaliação, podendo agravar o distanciamento na relação terapêutica, caso não haja apropriação devida desta realidade.

As falas dos AE extraídas do grupo focal nos ajudam a esclarecer melhor e objetivar o papel do estágio na mudança das representações, uma vez que nos possibilitam visualizar as representações antes e após o estágio (Quadro 1).

Percebe-se que as respostas são mais precisas e que os alunos falam sobre o tema com mais conforto e segurança, o que nos faz identificar a dinâmica de transformação do não-familiar em familiar, discutida por Oliveira ${ }^{38}$ e explicitada na teoria das representações sociais. Conforme Moscovici, ${ }^{16}$ "Ao nomear algo, nós o libertamos de um anonimato perturbador, para dotá-lo de uma genealogia e para

Quadro 1. Distribuição das teses e dissertações sobre Residências em Saúde, conforme as áreas dos programas onde foram produzidas, de 1987 a 2011

\begin{tabular}{|c|c|}
\hline Antes do estágio & Depois do estágio \\
\hline $\begin{array}{l}\text { Sentimento de pena } \\
\text { Medo de manuseio } \\
\text { Insegurança profissional } \\
\text { - Imediatismo do objetivo terapêutico } \\
\text {. Percepções banalizadas da realidade da deficiência } \\
\text { - Sentimento de tristeza }\end{array}$ & $\begin{array}{l}\text { - Abandono do sentimento de pena } \\
\text {. Percepção da capacidade de adaptação da realidade } \\
\text {. Percepção de que elas são felizes } \\
\text { - Percepção de sofrimento maior dos genitores } \\
\text { - Necessidade de manuseios } \\
\text { - Valorização dos ganhos físico-motores } \\
\text { - Visão global da criança deficiente } \\
\text { - Preocupação com os pais } \\
\text { - Valorização das técnicas } \\
\text { - Maior envolvimento com a criança } \\
\text { - Mudanças pessoais } \\
\text { - Preocupação com as adaptaçães e barreiras } \\
\text { - Troca de papéis } \\
\text { - Superação pessoal } \\
\text {. Percepção da superação da criança com DFM } \\
\text { - Maior respeito pela criança com DFM } \\
\text { - Lição de vida } \\
\text { Preocupação com o cuidar e tratar }\end{array}$ \\
\hline
\end{tabular}


incluí-lo em um complexo de palavras específicas, para localizá-lo, de fato, na matriz de identidade da nossa cultura". Quando algo não é facilmente compreendido, torna-se confuso, difuso, e não permite nem a sua melhor comunicação nem a sua ligação a outras imagens.

“... antes tinha muita pena... trabalhando com as crianças... elas são felizes do jeito que elas são... eu parei de ter pena de criança deficiente, eu acho que os pais sofrem muito mais do que a própria criança...". (AE2 1)

"A primeira visão que a gente tem mesmo é de pena, antes de ter o conhecimento". (AE2 4)

Ao reagruparmos as categorias surgidas nas falas dos $A E 2$, a análise possibilitou três unidades de sentido sobre o que mudou após o estágio: as mudanças pessoais, mudanças com relação à prática, e mudanças na forma de ver a criança com DFM (Quadro 2).

Quadro 2. Unidades temáticas - mudanças nas representações acerca da criança com DFM - AE2

\begin{tabular}{|c|c|}
\hline Unidades temáticas & Categorias \\
\hline Mudanças pessoais & $\begin{array}{l}\text { Abandono do sentimento de pena } \\
\text {. Percepção de que elas são felizes } \\
\text {. Percepção de sofrimento maior dos genitores } \\
\text {. Mudanças pessoais } \\
\text { - Troca de papéis } \\
\text { Superação pessoal } \\
\text {. Lição de vida } \\
\text { Maior respeito pela criança com DFM }\end{array}$ \\
\hline Mudanças profissionais & $\begin{array}{l}\text { Valorização das técnicas } \\
\text {. Preocupação com os pais } \\
\text {. Maior envolvimento com a criança } \\
\text {. Preocupação com o cuidar e tratar } \\
\text {. Valorização dos ganhos físico-motores }\end{array}$ \\
\hline Mudanças na forma de ver a criança & $\begin{array}{l}\text { - Percepção da capacidade de adaptação da realidade } \\
\text {. Necessidade de manuseios } \\
\text {. Visão global da criança deficiente } \\
\text {. Percepção da superação da criança com DFM }\end{array}$ \\
\hline
\end{tabular}

Não há, nas falas, a compreensão reduzida ao ponto de vista técnico e biomédico, o que dá, ao estágio supervisionado, um valor não somente da vivência intersubjetiva, mas da possibilidade de construção do conhecimento a partir da interação de outros paradigmas teórico-científicos das ciências humanas e sociais discutidos e vivenciados no estágio. Nota-se que a mudança nas representações sobre a criança com DFM é percebida em declarações que vêm atreladas às mudanças também profissionais, como: valorização das técnicas de intervenção, maior envolvimento com a criança e seus pais e preocupação com o cuidar e tratar. Valores e atitudes humanizadas que vão ao encontro do desejado pelas $\mathrm{DCN}^{\prime} \mathrm{s}^{39}$ para o perfil de egresso que vai atuar em diferentes frentes de atendimento à população, e que, gradativamente, vem preenchendo as equipes dos núcleos de saúde da família, o que, para Silva e Da Ros, ${ }^{40}$ apresenta-se como um grande desafio na formação dos profissionais de fisioterapia. 


\section{Fatores atribuídos às transformações das representações}

Os $A E$ atribuem as mudanças na forma de ver e pensar a deficiência: ao próprio contato físico com a criança com DFM e seu cotidiano, ao conhecimento adquirido no estágio supervisionado, e à síntese pessoal, uma vez que cada um é capaz de atribuir valores ao que vive e retirar dessas vivências o que achar pertinente, na medida em que se possibilita transformar.

\footnotetext{
“Cada um vai construindo o seu conteúdo... todo mundo passou pelo mesmo estágio, praticamente, mas cada um saiu com uma percepção, um pensamento...". (AE2 2)

"Você vivendo nunca é igual a alguém contar pra você" ... "É a prática que te dá experiências". (AE2 1)

"Só a prática mesmo... o conteúdo teórico não proporciona essas experiências...". (AE2 2)
}

A valorização do estágio supervisionado pelos $A E 2$, em relação às transformações desses sentimentos, é associada à importância do supervisor de estágio. Atributos como paixão pela área, dedicação, confiança, interesse e criatividade, são apresentados como essenciais na relação professor-aluno.

"O estágio é muito importante desde que o nosso orientador, nosso supervisor de estágio, seja bom e interessado e criativo." (AE2 4)

Os alunos observam que as ações pedagógicas propostas pelo supervisor de estágio são essenciais para manter o interesse pelo estágio e o aproveitamento integral durante sua prática. A partir da análise das falas, pudemos, em síntese, inferir que estas ações pedagógicas valorizadas pelos alunos são baseadas nos seguintes princípios norteadores: vínculo afetivo, observância, autonomia, respeito, ludicidade e autoridade.

O vínculo afetivo se constrói como primeiro passo no processo terapêutico. Num primeiro momento durante a prática de estágio, o aluno é orientado a realizar a leitura de prontuários dos pacientes que estarão sob seus cuidados terapêuticos, e, a partir daí, se estabelece o primeiro contato com a criança com DFM. Como a afetividade é apontada como um princípio gerador de confiança, os alunos destacam a liberdade de trocar os pacientes conforme a afinidade e a adaptação ao terapeuta como uma importante ação pedagógica. Nesse período é também estabelecido o contato com os pais ou com o cuidador que traz essa criança à fisioterapia.

... pra ela (a criança) parece que é uma brincadeira, que não é um tratamento, ela sai feliz da vida, gosta de você, quer voltar para o tratamento... e ao mesmo tempo você avaliou e tratou... brincando com ela... criando esse vinculo que é importante". (AE2 1)

“... o principal era a liberdade que ele (supervisor de estágio) dava pra gente trabalhar... caso uma criança não se adaptasse... às vezes um ajudava o outro... a gente fez estágio todo mundo junto no mesmo grupo... às vezes uma criança ficava mais a vontade com outro estagiário e a gente podia trocar... então deixa que eu vou ficar com ela e você atende meu outro paciente que é no mesmo horário". (AE2 4)

A capacidade de observância da criança também é uma conquista que pode ser proporcionada pelo estágio em relação ao olhar terapêutico. O aluno passa a ver a deficiência sob uma nova perspectiva, considerando a complexa dinâmica do conhecer, do reconhecer as diferenças e do tratar. Na prática terapêutica, o aluno é orientado a respeitar a vontade e a limitação da criança, mas sempre na tentativa de explorar os objetivos terapêuticos, mesmo indiretamente, sem que a criança perceba que está sendo tratada e associe o tratamento ao brincar. 
"Sempre brincando... trabalhando e brincando... tinha que ser assim, senão não ia... cada paciente você tem uma forma de se tratar... não é um protocolo". (AE2 1)

Logo, a ludicidade, já apresentada por Takatori ${ }^{41}$ como importante ferramenta para a intervenção em reabilitação de crianças com DFM, ocupa lugar fundamental na medida em que amplia as possibilidades de interação, envolvimento e prazer internalizado. O aluno passa a experimentar e reviver o brincar reforçando o vinculo afetivo, a criatividade e a autonomia.

Por outro lado, o lúdico também é visto como uma ferramenta que traz maior dificuldade dentro do estágio, já que demanda criatividade e predisposição na construção das brincadeiras, respeitando os objetivos que precisam ser alcançados e, também, as limitações e capacidades de cada criança frente as suas deficiências.

"Eu acho que o lúdico é o mais difícil pra gente, tanto na avaliação quanto no tratamento". (AE2 2)

A autonomia para a construção da proposta terapêutica, baseada no conhecimento teórico e na vivência com a criança, também é um fator importante durante o estágio na área, incentivando a criatividade e proporcionando segurança profissional, mesmo com o acompanhamento do supervisor durante a execução das manobras e na discussão das propostas. A elaboração da prática terapêutica se dá pelo próprio aluno, sem perder o foco nos objetivos de tratamento a curto, médio e longo prazo discutidos e traçados.

“... ele (supervisor do estágio) sempre deixou a gente muito livre... pra atender da maneira que a gente achava e se caso ele discordasse ele sempre sentava depois para discutir... bom eu acho melhor fazer assim ou fazer assado.... mas a gente sempre teve liberdade para trabalhar da maneira que a gente achasse melhor". (AE2 4)

"A gente acabou desenvolvendo uma maneira de trabalhar... cada um desenvolveu uma maneira de trabalhar... cada um começou a desenvolver, por conta dessa liberdade, de cada um poder fazer o que quisesse... a gente começou a desenvolver padrões nossos de tratamento". (AE2 2)

Os alunos, ao valorizarem a oportunidade da criatividade no tratamento, consideram a sua capacidade em elaborar novas técnicas e, ao mesmo tempo, pensar novos usos para as técnicas já existentes, o que significa que estão construindo conhecimento. Esta perspectiva é o resultado de uma pedagogia da práxis defendida por Gadotti ${ }^{28}$, aplicada aqui na intenção de se pensar a realidade da intervenção em saúde não como realidades dadas e que devem ser reajustadas ao conhecimento sistematizado, mas como realidades das quais algo já se conhece, mas muito há para se conhecer, mesmo porque a própria certeza deste real é constantemente relativizada e reconstruída.

Por fim, os alunos destacam o respeito como um importante princípio na mediação pedagógica do supervisor. O respeito à criança, seus limites e sua vontade, respeito aos pais ou cuidadores, respeito aos colegas de estágio e ao próprio supervisor. Aprender a respeitar envolve mudança no olhar, na maneira de ver o outro e na reflexão sobre as representações sociais e as próprias representações. $O$ respeito relaciona-se diretamente com o princípio da alteridade, ${ }^{38}$ que reconhece, no outro, a diferença e, ao mesmo tempo, a parte constitutiva de nós mesmos, o que se torna tão necessário na prática educativa.

“Você tem que olhar pelo olho da criança e não pelo seu olhar adulto... a criança que é o ponto principal". (AE2 3)

A autoridade durante o processo terapêutico também foi vivenciada pelo aluno durante o estágio com a criança com DFM. A autoridade apresenta-se como o maior desafio, já que é importante 
equilibrar o querer da criança e o fazer terapêutico sem comprometer o vínculo afetivo e mantendo o interesse da criança pelo lúdico e pelas propostas terapêuticas.

“Você encontrar a medida certa... assim na questão da firmeza... não adianta você só brincar, você tem que ter uma firmeza, a criança tem que te respeitar... e você encontrar essa medida de equilíbrio aí, foi uma coisa que com essa liberdade a gente tinha que conseguir". (AE2 5)

\section{Considerações finais}

\footnotetext{
"A pediatria vai estar sempre no meu coração... pra sempre". (AE2 3)
}

Este estudo procurou analisar as representações dos alunos do estágio em fisioterapia acerca da DFM em crianças, verificando possíveis transformações ao longo da sua formação acadêmica, tendo em vista o papel do estágio curricular nesse processo e as implicações para a prática profissional.

Observamos que a relação aluno e criança com DFM, durante o estágio em pediatria, é fator crucial para reduzir os aspectos negativos, bem como atribuir novos valores a essas crianças. A apropriação da linguagem técnica adquirida em todo o período formativo-teórico é agregada a fundamentos psicossociais a partir da vivência com a criança com DFM, permitindo o esvaziamento das preconcepções que dão origem ao estigma e o deslocamento, mesmo que gradual, de uma caracterização cristalizada socialmente para uma representação que permita ver as possibilidades, e não as desgraças. Para Goffman ${ }^{10}$, esse movimento assume a passagem da identidade social virtual para a identidade social real, esta última caracterizada pela categoria e os atributos que os indivíduos provam possuir. Os sentimentos de pena e tristeza cedem lugar ao conhecimento de um novo universo, a possibilidade de funcionalidade, evolução e de alegria num quadro antes interpretado como cheio de limitações.

A formação em saúde, especificamente em fisioterapia, considerando a visão multi e transdisciplinar com peso curricular distribuído de forma a atender o enfoque integral desejado pelas DCN's para a conduta profissional, é hoje o principal desafio para as instituições de Ensino Superior. Considerando que representações e ações são forças que se completam e se fortalecem na coexistência, as reflexões contínuas são necessárias para se estabelecer a ruptura e novas configurações. Por isso, a necessidade do conflito reafirmada por Moscovicij6 para as representações sociais.

Representações e ações não refletidas acabam reforçando uma cadeia viciosa de distanciamento, tanto pelo ponto de vista do desejo profissional de intervir na área da DFM quanto pela dificuldade em lidar com respostas físicas distanciadas das idealizadas pelos protocolos de reabilitação. Muitas vezes, não se conhece o outro, mas inicia-se a terapêutica com certezas e classificações a priori. Entretanto, o "ser" deficiente e o "sentir-se" deficiente são perspectivas que vão se (re)traduzindo conforme as experiências das próprias pessoas com DFM, o que, muitas vezes, vai conferindo novos sentidos para a deficiência ${ }^{42}$.

É neste contexto que a alteridade se faz necessária para reconhecer o outro, ouvir as suas necessidades, sem que sejam prejulgadas as diferenças, sem que o tratamento seja evitado ou diferenciado por conta da não-familiarização com a deficiência.

Conclui-se que o currículo em fisioterapia deve buscar a interface entre as diferentes áreas do conhecimento, valorizando, ainda mais, as ciências humanas e buscando a dinâmica entre teoria e prática para ação e reflexão sobre os diversos campos de atenção à saúde. O estágio como conhecimento e práxis deve ser incentivado, especialmente, o estágio em Fisioterapia Pediátrica, uma vez que os ganhos extrapolam a mudança na forma de ver a criança com DFM, trazendo benefícios e recursos profissionais incomparáveis, além de valores pessoais essenciais para a formação humana, integral e pautada numa cidadania mais crítica e emancipada. O estudo, por ter caráter qualitativo, contou com um número limitado de estudantes, o que não representa o universo dos alunos em formação. Os resultados apresentam indicadores relevantes sobre o papel do estágio na formação crítica, e apontam a necessidade de ampliação das informações, a partir de pesquisas continuadas de avaliação de métodos de ensino em saúde. 


\section{Colaboradores}

Leandro Dias de Araujo foi idealizador do tema e responsável pela elaboração do artigo, de sua discussão e redação e da revisão do texto. Ana Lucia de Souza Freire Santos responsabilizou-se pela revisão de literatura sobre deficiência. Adriano Rosa fez a revisão final do texto. Marta Corrêa Gomes orientou o processo de elaboração e trabalhou no desenvolvimento e conclusão do trabalho.

\section{Referências}

1. Araujo LDA. O estágio curricular como práxis pedagógica: representações sociais acerca da criança com deficiência físico-motora entre alunos de fisioterapia [dissertação]. Rio de Janeiro: Universidade Gama Filho; 2013.

2. Presidência da República. Casa Civil. Subchefia para Assuntos Jurídicos. Decreto $n^{\circ}$ 3.298, de 20 de dezembro de 1999. Regulamenta a Lei no 7.853, de 24 de outubro de 1989, dispõe sobre a Política Nacional para a Integração da Pessoa Portadora de Deficiência, consolida as normas de proteção, e dá outras providências [Internet]. Brasília, DF: Presidência da República; 1999. [acesso 2013 Dez 20]. Disponível em: https://www. planalto.gov.br/

3. Referencial Curricular Nacional para a educação infantil: estratégias e orientações para a educação de crianças com necessidades educacionais especiais. Brasília, DF: MEC/SEF; 2000.

4. Israel VL, Bertoldi LS. Deficiência físico-motora: interface entre educação especial e repertório funcional. Curitiba: Ipbpex; 2010.

5. Maia ACB. A importância das relações familiares para a sexualidade e a autoestima de pessoas com deficiência física. Portugal; 2010 [acesso 2013 Dez 20]. Disponível em: http://www.psicologia.com.pt/artigos/textos/A0515.pdf

6. Pereira RJ. Anatomia da diferença: uma investigação teórico-descritiva da deficiência à luz do cotidiano [tese]. Rio de Janeiro: Escola Nacional de Saúde Pública, Fiocruz; 2006.

7. Omote S. Deficiência e não deficiência: recortes do mesmo tecido. Rev Bras Educ Esp. 1994; 1(2):65-73.

8. Le Breton D. A sociologia do corpo. Petrópolis: Vozes; 2006.

9. Stoer S, Magalhães AM, Rodrigues D. Os lugares da exclusão social. São Paulo: Cortez; 2004.

10. Goffman E. Estigma: notas sobre a manipulação da identidade deteriorada. 4a ed. Rio de Janeiro: Guanabara; 1988.

11. Vaitsman J. Desigualdades sociais e duas formas de particularismo na sociedade brasileira. Cad Saude Publica. 2002; 18 Supl:37-46.

12. Omote S. Estigma no tempo da inclusão. Rev Bras Educ Esp. 2004; 10(3):287-308.

13. Othero $M B$, Dalmaso ASW. Pessoas com deficiência na atenção primária: discurso e prática de profissionais em um centro de saúde-escola. Interface (Botucatu). 2009; 3(28): 177.

14. Musis CR, Carvalho SP. Representações sociais de professores acerca do aluno com deficiência: a prática educacional e o ideal do ajuste à normalidade. Educ Soc. 2010; 31(1110):201-17.

15. Lomônaco JFB, Cazeiro APM, Ferreira AM. Concepções de deficiência e reabilitação: um estudo exploratório com graduandos de Fisioterapia. Psicol Esc Educ. 2006; 10(1):83-97. 
16. Moscovici S. Representações sociais, investigações em psicologia social. Petropólis: Vozes; 2003.

17. Berger P, Luckamann TA. construção social da realidade. Petrópolis: Vozes; 1973.

18. Rodrigues J. Tabu do corpo. Rio de Janeiro: Achiamé; 1983.

19. Ceccim RB, Feuerwerker L. Mudança na graduação das profissões de saúde sob o eixo da integralidade. Cad Saude Publica. 2004; 20(5):1400-10.

20. Barros FBM. A formação do fisioterapeuta na UFRJ e a profissionalização da fisioterapia [dissertação]. Rio de Janeiro: Instituto de Medicina Social, Universidade do Estado do Rio de Janeiro; 2002.

21. Cunha JHSC. A representação social do curso de fisioterapia: a visão do formando [dissertação]. Blumenau: Universidade Regional de Blumenau; 2006.

22. Pfister APL. A formação pedagógica dos professores de fisioterapia de uma Universidade do Estado de Minas Gerais: um estudo de caso [dissertação]. Franca: Universidade de Franca; 2006.

23. Teixeira LJ, Oliveira MAC. Estágios curriculares em fisioterapia. Fisioter Bras. 2007; 8(1):57-63.

24. Morais EGM. Docência universitária: o professor fisioterapeuta no curso de fisioterapia [dissertação]. Uberlândia: Universidade Federal de Uberlândia; 2008.

25. Moraes $M$. Discursos sobre as práticas no contexto da formação de fisioterapeutas no Rio Grande do Sul [dissertação]. Porto Alegre: Universidade Federal do Rio Grande do Sul; 2009.

26. Almeida ALJ, Guimarães RBO. O lugar social do fisioterapeuta brasileiro. Rev Fisioter. Pesqui. 2009; 16(1):82-8.

27. Nascimento Neto CD. Projeto pedagógico do curso de fisioterapia da Universidade do Oeste de Santa Catarina: uma leitura do processo de reconstrução da proposta curricular [dissertação]. Joaçaba: Universidade do Oeste de Santa Catarina; 2011.

28. Gadotti M. Pedagogia da práxis. 4a ed. São Paulo: Cortez, Instituto Paulo Freire; 2004.

29. Pimenta SG. O estágio na formação de professores: unidade teórica e prática? 3a ed. São Paulo: Cortez; 2005.

30. Mattos RA. A integralidade na prática (ou sobre a prática da integralidade). Cad Saude Publica. 2004; 20(5):1411-6.

31. Becker HS. Métodos de pesquisa em Ciências Sociais. São Paulo: Hucitec; 1993.

32. Minayo MCS. O desafio do conhecimento: pesquisa qualitativa em saúde. 12a ed. São Paulo: Hucitec; 2010.

33. Morgan DL. Focus groups as qualitative research. 2nd ed. London: Sage; 1997. (Qualitative research methods, v.16).

34. Bardin L. Análise de conteúdo. Lisboa: Edições 70; 1979.

35. Ministério da Saúde. Conselho Nacional de Saúde. Resolução n.196/96, de 10 de outubro de 1996. Estabelece as diretrizes e normas regulamentadoras de pesquisas envolvendo seres humanos. Diário Oficial da República Federativa do Brasil. 1996 Out. 16; Seção 1:21082-5.

36. Moscovici S. Prefácio. In: Guareschi P, Jovchelovitch S. Textos em representações sociais. Petrópolis: Vozes; 1994. p. 7-25.

37. Gusmão N. Linguagem, cultura e alteridade: imagens do outro. Cad Pesqui. 1999; (107):41-78. 
38. Oliveira AAS. O conceito de deficiência em discussão: representações sociais de professores especializados. Rev Bras Educ Esp. 2004; 10(1):59-74.

39. Ministério da Educação. Resolução n CNE/CES 4, de 19 de fevereiro de 2002. Estabelece as Diretrizes Curriculares Nacionais do Curso de Graduação em Fisioterapia [acesso 2013 Dez 20]. Disponível em: http://portal.mec.gov.br/cne

40. Silva DJ, Da Ros MA. Inserção de profissionais de fisioterapia na equipe de saúde da família e Sistema Único de Saúde: desafios na formação. Cienc Saude Colet. 2007; 12(6):1673-81.

41. Takatori M. O brincar no cotidiano da criança com deficiência física: privilegiando um olhar para a construção das intervenções em reabilitação [dissertação]. São Paulo: Universidade de São Paulo; 1999.

42. Martins JA, Barsaglini RA. Aspectos da identidade na experiência da deficiência física: um olhar socioantropológico. Interface (Botucatu). 2011; 15(36):109-21.

Araujo LD, Santos ALSF, Rosa A, Gomes MC. La pasantía curricular como praxis pedagógica: representaciones sociales sobre los niños con deficiencia físico-motora entre estudiantes de Fisioterapia. Interface (Botucatu). 2014; 18(48):151-64.

El artículo analiza la transformación de las representaciones sociales de los alumnos de fisioterapia sobre el niño con deficiencia físico-motora, influenciada por la pasantía en fisioterapia pediátrica. Para la problematización consideramos el modo estigmatizado en que las personas con deficiencias son representadas y la influencia de la pasantía curricular supervisada en la formación académica en salud. La encuesta, de carácter cualitativo, se realizó con 24 alumnos ingresados y formados en fisioterapia pediátrica que realizaron entrevistas semi-estructuradas y grupo focal. El estudio permitió la inferencia de que las representaciones son fundamentalmente posibilitadas por la experiencia de la pasantía, aunque las disciplinas teórico-conceptuales suministren subsidios técnicos para la intervención. De esa forma, el currículum debe dar énfasis a la pasantía como conocimiento y praxis, puesto que los beneficios extrapolan el cambio en la manera de ver la discapacidad, proporcionando beneficios y recursos profesionales incomparables, además de valores esenciales para la formación humana.

Palabras-clave: Educación. Formación en salud. Fisioterapia. Rehabilitación. Niños. 